\title{
Research on Key Technologies and Development Status of Cross Border E-commerce
}

\author{
Yongliang $\mathrm{Li}^{1, \mathrm{a}}$ and Kaifeng Huang ${ }^{1}$ \\ ${ }^{1}$ Luoyang Normal University, Henan Luoyang, 471934, China \\ aliyongliangls@163.com
}

\begin{abstract}
Keywords: Cross border E-commerce; B2B; International Trade; Online auction; Economic integration
\end{abstract}

\begin{abstract}
Cross border e-commerce not only broke through the barriers between countries, so that international trade to trade without borders, but it is also causing great changes in world economic and trade. Cross-border electronic business platform is divided into information services platform and online trading platform. This paper analyzes the development process of cross-border e-commerce, and points out the existing problems. The paper proposes research on key technologies and development status of cross border E-commerce.
\end{abstract}

\section{Introduction}

In cross-border e-commerce supplier market, cross-border B2B mode in the overall cross-border electricity supplier industry is particularly important, playing a pillar role in the industry. And cross-border B2B platform transaction size has always accounted for more than $90 \%$ of the overall cross-border electricity supplier market trading scale. Cross-border electricity supplier is divided into two categories of exports and imports, which is currently mainly in the domestic sea Amoy service. Cross-border electricity supplier involved in the analysis of this report is sold outside the transaction, not including internal marketing services.

Engaged in cross-border import e-commerce supplier trade, relying on its free trade zone advantages, carry out the "free trade model", namely cross-border corporate bulk purchases of goods in foreign countries, cross-border positions formulated by sea delivery to the bonded area within the consumers through the Internet orders, business enterprise for the customs clearance formalities, goods to form personal items to declare a area. And pay parcel tax, Customs approved, goods parcel by express delivery to consumers.

In addition, the global market for Chinese made choice has gradually changed. On the choice of China manufacturing not only at a low price as a breakthrough point, but on product quality, brand Chinese manufacturing visibility, brand influence, credit degree, product prices and other factors into consideration [1]. The global market choice for the transformation of China manufacturing, and it is said the global market for further recognition Chinese manufacturing, and manufacturing of China with high expectations, but also show the core direction of the future development of cross-border electricity China.

Cross border e-commerce as a technical basis to promote economic integration, trade globalization, has very important strategic significance. Cross border e-commerce not only broke through the barriers between countries, so that international trade to trade without borders, but it is also causing great changes in world economic and trade [2]. For businesses, cross-border e-commerce to build an open, multi-dimensional, three-dimensional model of multilateral economic and trade cooperation has greatly widened the path to enter the international market, greatly promote the mutual benefit and optimize the allocation of resources between the multilateral enterprise; for consumers, cross-border E-commerce makes them very easy to get information from other countries and to buy high quality and inexpensive goods. 


\section{Development Model Analysis of Cross-Border E-Commerce Supplier}

In the 1 phase of cross-border electricity supplier, Alibaba international platform and global resources network as a typical representative platform. The Alibaba was founded in 1999, with the network information service, offline transactions meeting supplement, is one of the largest foreign trade information platform China yellow pages. Global resources network was established in 1971, formerly known as Asian Source, is an early Asian trading market information provider, and on the Nasdaq Stock Exchange, equity code GSOL.

As the first cross-border e-commerce supplier pilot city, the cross-border electricity supplier since 2013 has gradually become rational, but in 2014 as the first year of Chinese cross-border electricity supplier, for each big city pilot the opportunity take cities and seize territory, launched their corresponding cross-border business, or to import bonded, or direct purchase, or export, at the same time in logistics the enterprise of all major brands of commercial enterprises, as well as major retail enterprises have settled for different trends, show the scale.

As the state of cross-border e-commerce regulatory policy becomes clearer, the customs and the government tightened regulatory gaps, some of the traditional small and medium-sized foreign trade enterprises and individual sellers of cross-border electronic business platform to face the emerging regulatory policy gradually produced a sense of urgency [3]. This part of the foreign trade units have a common characteristic, long-term use in the tax on transportation routes, levy Butui, for the sun is not familiar with the chain of cross-border, cross-border supervision in the face of the arrival of the era is at a loss.

The fast growth of cross-border e-commerce started late in 2011, the global economic slowdown background, the overall size of China's cross-border e-commerce retail export more than $\$ 10$ billion, although only accounted for $0.5 \%$ of the total national export in 2011, but the year growth rate of over $100 \%$. The 2011 national electronic commerce up to 203 million users in 2009, cross-border e-commerce accounted for $13 \%$ of the total number of users of electronic business to calculate the 2011 cross-border e-commerce users reached 23 million 690 thousand, as is shown by equation (1).

$$
\left(P^{(\chi)}(1 \mid 1)\right)^{-1}=\left(P^{(\chi)}(1 \mid 0)\right)^{-1}+\Psi^{T}(1) \bar{R}^{-1}(1) \Psi(1)
$$

SNS is a distributed technology, popularly said to use P2P technology to build the next generation of personal based network infrastructure. SNS through distributed software programming will now be dispersed in each person's device on the CPU, hard disk, bandwidth to co-ordinate arrangements, and give this relatively small server equipment is more powerful [4]. These capabilities include: computing speed, communication speed, storage space.

In the 3 phase of cross-border e-commerce supplier, user groups from grassroots entrepreneurship to factories, foreign trade company's change, and has a strong production design management capabilities. Change the platform product sales network, from secondary sources to the primary sources of good products. For the 3 phase of the main seller group is in transition from the traditional foreign trade to cross-border business difficult, production mode change from the production line to flexible manufacturing, for supporting service demand generation operation and industrial chain high.

Zhengzhou is listed as the first national e-commerce model city and the first cross-border trade e-commerce services pilot city, is the only city of domestic and cross-border pilot comprehensive utilization of the bonded supervision places, can form a cross-border goods distribution center in Zhengzhou as the center, emerging e-commerce industry agglomeration effect, the city has 1 national e-commerce demonstration base, 5 provincial demonstration bases, 2 provincial-level industrial park.

From 2014 Chinese cross-border electricity supplier import structure, cross-border electricity supplier in the exports reached $86.7 \%$, the proportion of imports in $13.3 \%$, due to China's imports of cross-border electricity supplier started late, with the rise in domestic demand, the next few years is expected to cross-border electricity share of imports will continue to rise, but the policy implications, so the share of imports will rise steadily in the cross-border electricity supplier [5].

From the form of e-commerce transactions, pure electronic transactions to a large extent belong to the field of trade in services, international generally recognized as GATS rules in accordance with trade 
in services management. For e-commerce only through the way to complete the order, and it is contract, etc., but through the traditional mode of transport to the buyer to the location, then included in the category of goods trade, belonging to GATT management category.

\section{Cross Border E-Commerce Supplier Technology and Future Development Trend Analysis}

Cross border e-commerce supplier industry as a whole system, standardized imminent. Meanwhile, due to the particularity of cross-border electricity supplier, international relations, the entire cross-border international trade inherent interest structure and cross-border electricity supplier ecosystem will affect the development of cross-border electricity supplier market [6]. Chinese cross-border electricity supplier in this environment, policy support and policy perfection is particularly important.

Cross border e-commerce trade pilot model for online direct purchase of imported models, online shopping bonded import mode, the general export model, the city's cross-border electricity supplier lies in the direct purchase and bonded imports as well as general exports [7]. At present, Shanghai cross-border trade e-commerce platform (hereinafter referred to as "cross-border") since December 28 , 2013 on the line, and gradually improve the cross-border services three mode, has formed a direct mail China and free trade earning mode, cross-border sales of products are the main categories of maternal and child health food, bags, clothing, cosmetics, five categories of products, focus on FMCG field, commodity prices compared with the store, can offer about $30 \%$.

The main reason for the impact of e-commerce on international trade law is that the law applied to international trade is not perfect. The formulation of relevant legal system lags far behind the development of industry. Therefore, an urgent need to solve the problem is to develop a number of appropriate e-commerce laws to solve the various disputes arising on e-commerce, as is shown by equation (2).

$$
\hat{\beta}_{\mathrm{LS}}=\frac{\lambda^{\frac{1}{2}}}{\sigma_{s, s_{0}}} u=\mathrm{u}
$$

Cross border e-commerce and payment services to break the limits of time and space, business radiation to every corner of the world, so that economic and financial information and capital chain increasingly concentrated in the data platform [8]. Once the main body of the transaction lack of financial strength or illegal operation, credit crisis, and it is system failure, information leakage and other issues, and it will lead to customer foreign exchange funds risk. Therefore, cross-border e-commerce and payment services are to participate in the main subject of market access standardized management is extremely important and urgent.

Most of the social network will provide many ways to let users interact, including chat, mail, video, file sharing, blog and participate in the discussion group etc.. Social networking offers new ways to communicate and share information. General social networking sites have millions of users, the use of this service has become a part of the daily lives of many users.

\section{Research on the Combination of Cross Border E-Commerce and Social Network Services}

Cross-border electricity supplier has undergone significant changes, but to Dunhuang network, speed selling as the main platform for cross-border electricity supplier platform is still the main way to enter the cross-border electricity supplier industry. Meanwhile, self initiated cross-border B2C began to appear. At the same time, platform operators began to achieve the role of platform service provider transformation, information flow, logistics and capital flow third party integration services to join, improve platform services.

Public service e-commerce platform for cross-border trade on-line, cross-border business has become the focus direction of the development of modern service industry of Chongqing West Yongyong Microelectronics Industrial park [9]. To June 2014, public service e-commerce platform for cross-border trade data show that the first half of the time platform total clearance of listing 158 
thousand, turnover amounted to 44 million 566 thousand and 200 yuan, a total record of 36 enterprises, consumer goods become Chongqing using cross-border e-commerce way love procurement varieties.

Cross border B2C transaction amount has a certain limit, more than the required amount to pay tariffs; and overseas buyers using Visa and MasterCard credit card transactions can not be completed tax refund. Receivables to settlement there is a certain time difference, as is shown by equation (3), where $\mathrm{c}$ is the supplier may face fluctuations or loss of exchange rate [10].

$$
\left[\begin{array}{c}
x_{1} \\
x_{2} \\
\vdots \\
x_{M}
\end{array}\right]=\left[\begin{array}{cccc}
c_{11} & c_{12} & \cdots & c_{1 n} \\
c_{21} & c_{22} & \cdots & c_{2 n} \\
\vdots & \vdots & \ddots & \vdots \\
c_{M 1} & c_{M 2} & \cdots & c_{M n}
\end{array}\right]\left[\begin{array}{c}
u_{1} \\
u_{2} \\
\vdots \\
u_{n}
\end{array}\right]
$$

Cross-border e-commerce and payment of foreign exchange supervision system into the main body with the transition from the behavior regulation to supervision of the State Administration of foreign exchange supervision, proposed cross-border e-commerce and payment transaction subject into the foreign exchange supervision category, make full use of the existing supervision results of category management..

In the early Internet there are many services to support user interaction, such as BBS, newsgroups, etc.. Early social networking services website is in the form of online communities, users communicate through chat rooms. With the emergence of Blog and other social networking tools, users can share their information on the site's personal home page. Between 2002 and 2004, the world's three most popular social networking services sites are Friendster, MySpace, Bebo.

SN English full name Social Networking, that is, social networks (social networks), refers to the relationship between individuals network, which is based on the social networking system thinking website is a social networking site (SNS website). Many WEB2.0 sites now belong to SNS sites, such as IM, dating, video sharing, blogs, podcasts, online communities, music sharing, etc..

\section{Summary}

Currently cross-border e-commerce to export trading based. But with the rapid development of China's cross-border electricity market, user consumption habits gradually develop cross-border and cross-border business enterprise in the product category, quality and service and other aspects of the promotion and improvement of China's cross-border electricity market competitiveness will greatly enhance the export proportion will gradually balanced.

\section{References}

[1] Xiaojun WU, "The Application of Neural Network Technology in Electronic Commerce Evaluation System", JDCTA, Vol. 5, No. 12, pp. $233 \sim 239,2011$.

[2] Ci Jiaojin, " An Empirical Study of the Improvement of the Product Supply Chains in terms of Reducing Environmental Pollution in China", International Journal of u- and e- Service, Science and Technology Vol.8, No. 10 (2015), pp.169-178.

[3] Hyoung-Yong Lee, Hyunchul Ahn, "The Roles of Trust and Risk in Electronic Commerce Acceptance among Virtual Community Users", AISS, Vol. 5, No. 12, pp. 82 90, 2013.

[4] Qinglong Hu, " A Profit-Maximizing Economic Lot Scheduling Problem with Shelf Life Items", International Journal of u- and e- Service, Science and Technology Vol. 6, No. 3, June, 2013.

[5] Kun Fan, Jing Wu, Xinyu Ma, Weijia You, "Influencing Factors Analysis of Forest Farmers' Adoption of Forestry Electronic Commerce", JCIT, Vol. 8, No. 3, pp. 350 357, 2013.

[6] Taeho Kim, Gaewon Kim, Dai-Hwan Lim, Changhoon Yim, "U-Home Network Architecture Based on Cloud Computing", RNIS, Volume 12, pp. 161 164, 2013. 
[7] Dewu XU, Wei CHEN, "Analysis and Improvement of Signcryption Scheme Based on Identification in Electronic Commerce", JDCTA, Vol. 7, No. 2, pp. 89 98, 2013.

[8] K. Poonkavithail and A. Keerthika, "Unreliable Road Network Traffic Detection and Prevention", International Journal of u- and e- Service, Science and Technology Vol.8, No.5 (2015), pp.13-22.

[9] Wei Min, "A Research on Statistical Information Applied to Tourist Traffic and Transport System Design Based on ASP. NET", JCIT, Vol. 6, No. 1, pp. 147 156, 2011.

[10] Qiang Li and Hongfei Jia, " Fuzzy Multi-objective Expected Value Optimization Models for Locating an Automotive Service Enterprise", International Journal of u- and e- Service, Science and Technology Vol.9, No. 5 (2016), pp.77-88. 